\title{
Transpapillary EUS-guided retrograde puncture of the biliary tree as an alternative for failed rendezvous procedure
}

Endoscopic retrograde cholangiopancreatography (ERCP) is a first-line therapeutic method for obstructive biliary pathologies. Rarely, this procedure fails to obtain access and/or drainage of the biliary tree [1]. Until recently, such patients could be managed only via a percutaneous or surgical approach. An emerging alternative is endoscopic ultrasound (EUS)-assisted biliary access and drainage, namely rendezvous procedure. However, this technique is unsuccessful in $25 \%$ of patients [2].

We present a case of a 63 -year-old man with diagnosis of pancreatic head tumor, stage IIA (according to American Joint Committee of Cancer, seventh edition), who was scheduled for surgery when he developed acute cholangitis. The patient had undergone antrectomy and gastrojejunostomy with Billroth II reconstruction 20 years previously due to a pyloric stenosis. On the blood tests, he had elevated inflammatory parameters (17000 leucocytes $/ \mathrm{mm}^{3}$, 93\% neutrophils, C-reactive protein $9.5 \mathrm{mg} / \mathrm{dL}$ ) and cholestasis (alkaline phosphatase $472 \mathrm{U} / \mathrm{L}$, gamma-glutamyl transferase $1192 \mathrm{U} / \mathrm{L}$, alanine aminotransferase $222 \mathrm{U} / \mathrm{L}$, aspartate aminotransferase $105 \mathrm{U} / \mathrm{L}$, total bilirubin $9.4 \mathrm{mg} / \mathrm{dL}$, and direct bilirubin $7.9 \mathrm{mg} / \mathrm{dL}$ ). The imaging tests revealed a dilated common bile duct (CBD), with a diameter of $13 \mathrm{~mm}$.

An ERCP was attempted but cannulation was not achieved, although pre-cut was performed. Therefore, an EUS-guided transjejunal puncture of the CBD was performed using a 19-gauge needle ( $\bullet$ Fig. 1 ). The cholangiography showed dilation of the CBD as described above, with a distal stenosis. A 0.035-inch guidewire was then passed through the needle into the $\mathrm{CBD}$, but its constant proximal orientation prevented a rendezvous procedure ( $\bullet$ Fig.2). We then attempted an EUS retrograde approach, with direct puncture of the CBD, through the papilla and with fluoroscopic control ( Fig.3). A plastic stent $(10 \mathrm{Fr} / 5 \mathrm{~cm})$ was placed, resulting in immediate output of bile and pus ( $\bullet$ Figs.4-8). The patient recovered well clinically and underwent cephalic duodenopancreatectomy 1 week later.

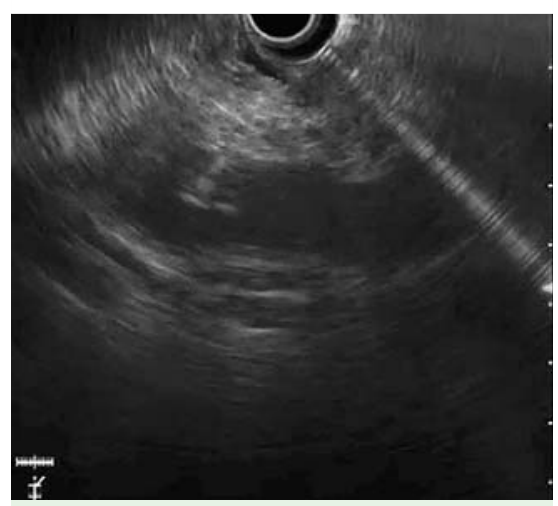

Fig. 1 Transjejunal endoscopic ultrasoundguided puncture of the distal common bile duct with a 19-gauge needle.

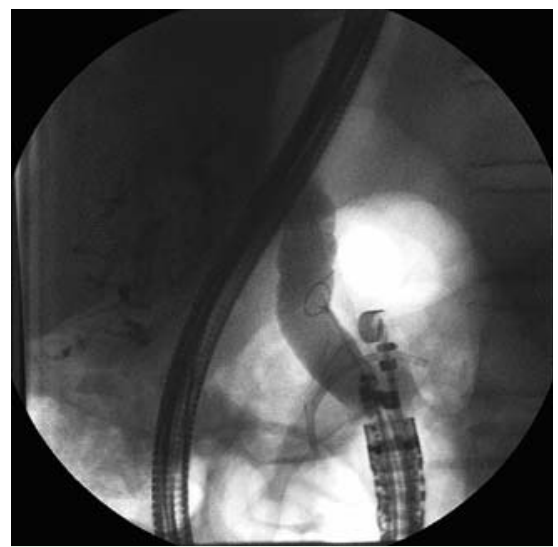

Fig. 3 The endoscopic ultrasound retrograde approach, with direct puncture of the common bile duct, through the papilla and with fluoroscopic control.

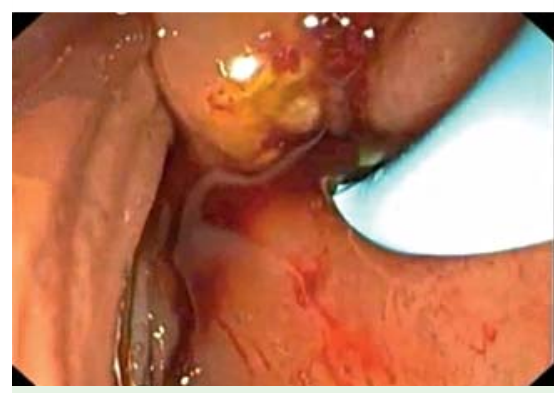

Fig. 5 Endoscopic view of plastic stent placement.

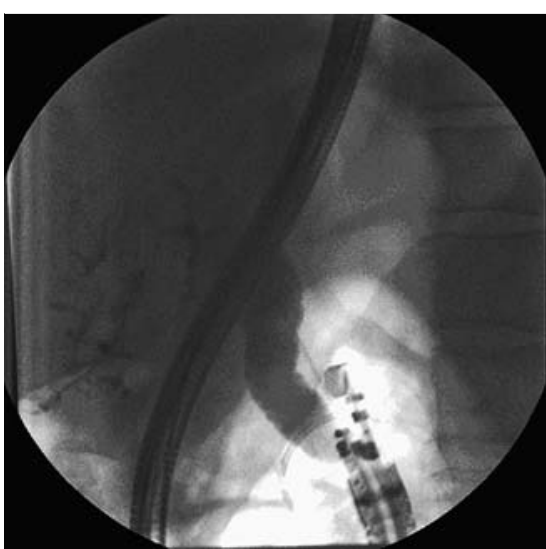

Fig. 2 Constant proximal guidewire orientation prevented the rendezvous procedure.

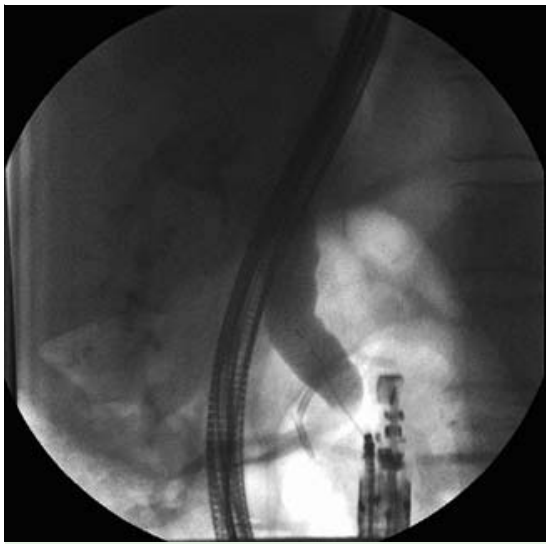

Fig.4 Guidewire introduced through the echoendoscope into the common bile duct.

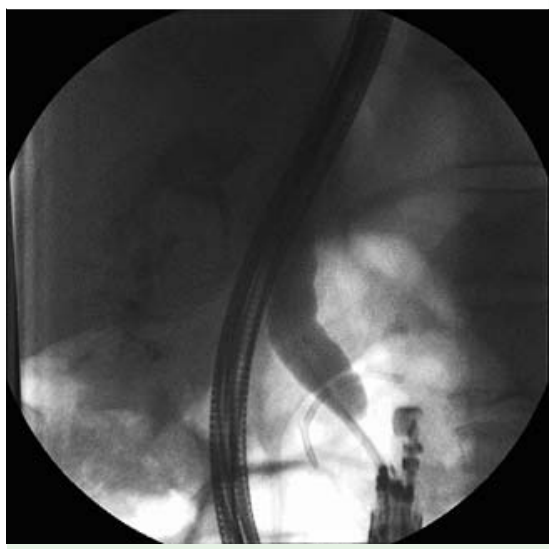

Fig. 6 Fluoroscopic view of plastic stent placement. 


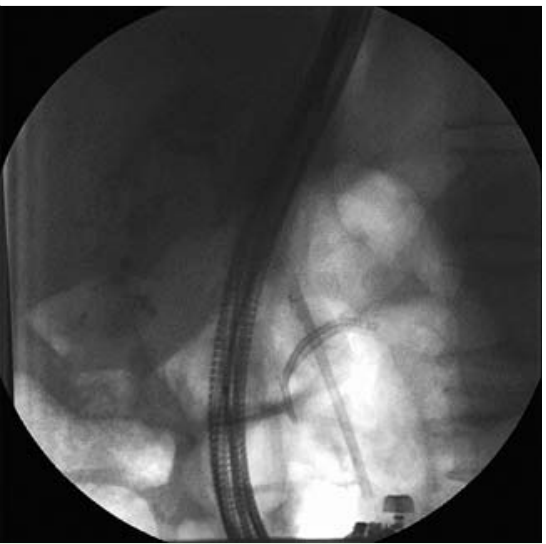

Fig. 7 Plastic stent in common bile duct.

Advances made in EUS have enabled the implementation of various methods of alternative access to the biliary tree [35]. In this case, we demonstrated that an EUS-guided retrograde approach to the biliary tree, through the papilla and with fluoroscopic control, is a feasible technique for decompressing the biliary tree when rendezvous fails.

Endoscopy_UCTN_Code_TTT_1AR_2AC

Competing interests: None

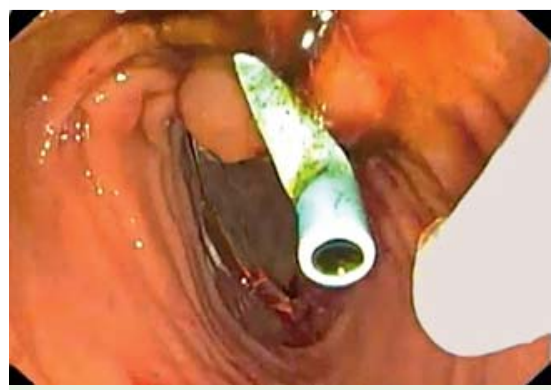

Fig. 8 Efficient drainage of the biliary tree.

Vera Costa Santos, Nuno Nunes, Filipa Ávila, Ana Catarina Rego, José Renato Pereira, Nuno Paz, Maria Antónia Duarte

Gastroenterology, Hospital do Divino Espírito Santo de Ponta Delgada,

Ponta Delgada, Portugal

\section{References}

1 Enochsson L, Swahn F, Arnelo $U$ et al. Nationwide, population-based data from 11,074 ERCP procedures from the Swedish Registry for Gallstone Surgery and ERCP. Gastrointest Endosc 2010; 72: 1175-1184

2 Shah JN, Marson F, Weilert $F$ et al. Singleoperator, single-session EUS-guided anterograde cholangiopancreatography in failed
ERCP or inaccessible papilla Gastrointest Endosc 2012; 75: 56-64

3 Bories E, Pesenti C, Caillol F et al. Transgastric endoscopic ultrasonography-guided biliary drainage: results of a pilot study. Endoscopy 2007; 39: 287-291

4 Will U, Thieme A, Fueldner F et al. Treatment of biliary obstruction in selected patients by endoscopic ultrasonography (EUS)-guided transluminal biliary drainage. Endoscopy 2007; 39: $292-295$

5 Weilert F, Binmoeller KF, Marson $F$ et al. Endoscopic ultrasound-guided anterograde treatment of biliary stones following gastric bypass. Endoscopy 2011; 43: 1105-1108

\section{Bibliography}

DOI http://dx.doi.org/

10.1055/s-0033-1359141

Endoscopy 2014; 46: E93-E94

(c) Georg Thieme Verlag KG

Stuttgart · New York

ISSN 0013-726X

\section{Corresponding author}

Vera Costa Santos, MD

Gastroenterology

Hospital do Divino Espírito Santo de Ponta Delgada Rua Professor Alfredo Bensaude, $n^{\circ} 10,1^{\circ}$ direito 9500-700 Ponta Delgada Portugal

Fax: +351-967-358334

vera@multi.pt 